\title{
Commentary: Is the juice worth the squeeze?
}

\author{
Gurion Lantz, MD, and Frederick A. Tibayan, MD
}

Cardiothoracic surgery is an expansive and rapidly changing field with an ever-growing body of knowledge to internalize before completion of training. Preparation for the American Board of Thoracic Surgery (ABTS) certifying exam is more demanding than ever, with the ongoing addition of endovascular, hybrid, and transcatheter therapies; advances in thoracic oncology, including improving medical therapy and changes in staging; and a growing body of important literature always adding to the long list of topics covered in the exam. There is no single textbook that covers all of the relevant material in an annually updated fashion. The Core Curriculum Review Course in Cardiovascular and Thoracic Surgery has long served a useful role for trainees and new attending physicians by presenting a concise and consolidated overview of all relevant topics in thoracic, cardiac, and congenital cardiac surgery.

The central question of a Board review course is whether or not completion of the program will improve one's chances of passing the exam. Doty and colleagues ${ }^{1}$ compared performance before and 50 days after the 4-day review course on multiple choice tests constructed to represent the content on the ABTS certifying exam. They found that there was a $14 \%$ improvement in test performance amongst course participants who chose to take both optional exams. How much improvement might we have seen over 7 weeks without the Core Curriculum Review? The design of the study makes it difficult to determine the effect of the course. The tests were not mandatory, and the testing conditions

\footnotetext{
From the Division of Cardiothoracic Surgery, Department of Surgery, Oregon Health and Science University, Portland, Ore.

Disclosures: The authors reported no conflicts of interest.

The Journal policy requires editors and reviewers to disclose conflicts of interest and to decline handling or reviewing manuscripts for which they may have a conflict of interest. The editors and reviewers of this article have no conflicts of interest.

Received for publication Aug 4, 2021; revisions received Aug 4, 2021; accepted for publication Aug 6, 2021; available ahead of print Sept 2, 2021.

Address for reprints: Frederick A. Tibayan, MD, Division of Cardiothoracic Surgery, Department of Surgery, Oregon Health and Science University, 3181 SW Sam Jackson Park Rd, Mail code: L353, Portland, OR 97239 (E-mail: tibayan@ohsu. edu).

JTCVS Open 2021;7:287-8

2666-2736

Copyright (C) 2021 The Authors. Published by Elsevier Inc. on behalf of The American Association for Thoracic Surgery. This is an open access article under the CC BY-NCND license (http://creativecommons.org/licenses/by-nc-nd/4.0/).

https://doi.org/10.1016/j.xjon.2021.08.009
}

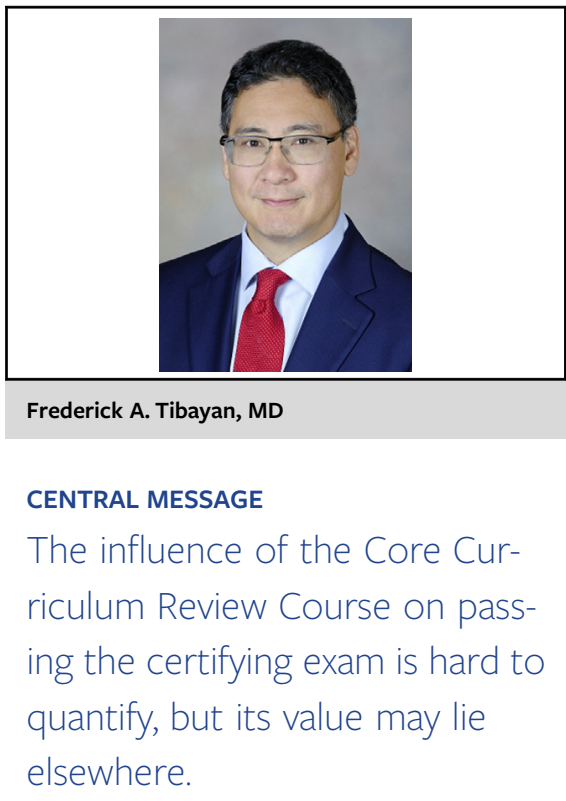

were not standardized. The lack of a control group and the 7 -week interval between the course and the posttest also confound interpretation of the results, especially given that most resident physicians are expected to ramp up studying as the exam approaches. ${ }^{2}$ Despite the limitations in the design and execution of the study, a current and comprehensive review of all relevant and current material holds value before taking the certifying exam. Enrolling in the course also serves as a way for many to force themselves to prepare. In addition, although originally intended for exam preparation, the course materials, which are updated regularly, could be used throughout residency training to identify knowledge deficits and gauge improvement.

The authors have many opportunities to build on this study. Increasing sample size, standardizing the testing format, and scheduling the posttest immediately following the 4-day review would all help quantify the influence of the course. Notably, a prospective survey of American Board of Surgery examinees found no evidence that taking a board review course improved passing rate for the certifying exam. ${ }^{3}$ Even in the case that the same is true for the Core Curriculum Review Course and the ABTS, other effects, such as psychological motivation and efficiency of preparation, are not to be overlooked. In the end, it will be up to individual examinees to determine whether the juice is worth the squeeze.

\section{References}

1. Doty JR, Nguyen M, Snyder RJ, Doty DB. Impact of a focused review course in cardiovascular and thoracic surgery on test performance. J Thorac Cardiovasc Surg Open. 2021;7:274-85. 
2. Pletch A, Craig W, Rappold, Whiting J, Turner C. Study strategies for general surgery residents preparing for the American Board of Surgery In-Training Examination: what to keep, discard, and adopt. J Surg Educ. 2021;78:43-9.
3. Jones AT, Biester TW, Lewis FR Jr, Malangoni MA. Review courses for the American Board of Surgery certifying exam do not provide an advantage. Surgery. 2015; 158:890-6. 